Journal of Antimicrobial Chemotherapy (1989) 23, 229-235

\title{
In-vitro toxoplasmacidal activity of cationic electron carriers
}

\author{
Hernan R. Chang and Jean-Clande Pechère \\ Department of Microbiology, University of Geneva Medical School, \\ C.M.U., 9 av. de Champel, 1211 Geneva 4, Switzerland
}

\begin{abstract}
Exposing murine macrophages infected with the protozoan parasite Toxoplasma gondil to micromolar concentrations of some cationic electron carriers (dyes), resulted in complete killing of the intracellular parasites at concentrations at which these compounds did not seem toxic for the macrophages. The $50 \%$ inhibitory concentrations (with $95 \%$ confidence limits) were calculated as $0.26(0.18-0.37)$, $1.35(1-2.25), 0.45(0.13-1.50)$, and $1.52(0.91-2.53) \mu \mathrm{M}$ for crystal violet, phenazine methosulphate, methylene blue and brilliant cresyl blue, respectively. The effects of these electron carriers did not appear to be the result of an enhancement of the natural antitoxoplasmic activity of the macrophages. None of the tested compounds was active against extracellular Tox. gondii as measured by ability to reinfect murine macrophages; thus, these dyes seem to act primarily on actively metabolizing, intracellular, Tox. gondii. Our data also suggest that the killing effect of the electron carriers was not related to the generation of reactive oxygen intermediates as judged by the inability of scavengers of these intermediates to block the activity against intracellular Tox. gondii. Further studies with related redox compounds would have an interesting chemotherapeutic perspective for treating toxoplasma infections.
\end{abstract}

\section{Introduction}

Toxoplasma gondii is a ubiquitous protozoan parasite which can cause disease in man. No satisfactory cidal therapy is available for treating life-threatening toxoplasma infections which can occur among patients with the Acquired Immune Deficiency Syndrome (AIDS).

It seems to be well established that components of the cellular immune response (mononuclear phagocytic system) are the main effectors of defence against this obligate intracellular parasite. Activated macrophages are able to kill Tox. gondii in vitro, and this killing seems to be associated with the ability of the mactophages to release reactive oxygen intermediates (ROI) such as superoxide anion, hydrogen peroxide and hydroxyl radical (Nathan et al., 1983; Murray, Spitalny \& Nathan, 1985). Studies have shown that cationic electron carriers, which are thought to undergo redox-cycling and generating superoxide anion and hydrogen peroxide (Hassan \& Fridovich, 1979), were able to inhibit intracellular Trypanosoma cruzi and Leishmania spp. (Rabinovitch et al., 1982; Alves \& Rabinovitch, 1983; Mauel, Schnyder \& Baggiolini, 1984). One of these electron carriers, the triarylmethane dye crystal violet (gentian violet), was shown to be active against extracellular Tryp. cruzi in vitro (Nussenzweig et al., 1953). Since then, this dye has been used by blood banks in Latin-American endemic countries in an attempt to reduce the transmission of Chagas' disease. The mechanism of action of 
these compounds, however, has not been elucidated. Here, the in-vitro activity of cationic electron carriers against extracellular and intracellular tachyzoites of Tox. gondii was investigated.

\section{Materials and methods}

\section{Animals}

Female Swiss-Webster mice (Madörin, Füllinsdorf, Switzerland), weighing 23 to $25 \mathrm{~g}$ each, were used in all experiments.

\section{Macrophages}

Animals were killed by $\mathrm{CO}_{2}$ asphyxiation, their resident peritoneal macrophages were harvested from their peritoneal cavities as described previously (Chang \& Pechère, 1988 ), and the concentration of mononuclear cells was adjusted to $2 \times 10^{6} / \mathrm{ml}$ with medium 199 (M199) supplemented with 10\% fetal calf serum (FCS) (pH 7.2). Each well of a 96-well tray (Costar, Cambridge, Massachussetts), or each chamber of fourchamber Lab-Tek slides (Lab-Tek Div., Miles Laboratories Inc., Naperville, Illinois), was seeded with $2 \times 10^{5}$ and $2 \times 10^{6}$ cells, respectively. They were incubated for $2-3 \mathrm{~h}$ at $37^{\circ} \mathrm{C}$ in a $5 \% \mathrm{CO}_{2}-95 \%$ air humid atmosphere. The nonadherent cells were discarded by washing twice with prewarmed Hanks' balanced salt solution (HBSS).

\section{Electron carriers}

The following electron carriers were obtained from Fluka AG, Buchs, Switzerland: brilliant cresyl blue (mol. wt, 385.96), crystal violet (mol. wt, 407.99), methylene blue (mol. wt, 319.86) and phenazine methosulfate (mol. wt, 306.34). They were dissolved in culture medium and sterilized by filtration immediately before use.

\section{Scavengers of oxygen intermediates}

Scavengers of oxygen intermediates (Catterall, Sharma \& Remington, 1986) were obtained from Sigma GmbH, Deisenhofen, West Germany, and used at the concentrations shown. Superoxide dismutase, $3000 \mathrm{U} / \mathrm{mg}(2.5 \mathrm{mg} / \mathrm{ml})$ was used for superoxide anion; catalase from bovine liver recrystallized twice $(2.5 \mathrm{mg} / \mathrm{ml})$ for hydrogen peroxide; and histidine $(10 \mathrm{mM})$ and diazabicyclooctane $(1 \mathrm{mM})$ for singlet oxygen radicals. The scavengers of hydroxyl radicals were benzoic acid (10 mM), mannitol $(50 \mathrm{mM})$ and tetramethylurea $(25 \mathrm{~mm})$. These scavengers were added to the monolayers immediately after the $1 \mathrm{~h}$ challenge with Tox. gondii and $30 \mathrm{~min}$ before the addition of the cationic electron carriers. All these experiments were performed over a 24-h period of incubation.

\section{Tox. gondii infection and microbicidal assays}

Cell cultures were challenged for $1 \mathrm{~h}$ with $2 \times 10^{5}$ (96-well trays) or $2 \times 10^{6}$ (Lab-Tek slides) RH strain Tox. gondii tachyzoites. After uningested parasites had been removed by washing, standard medium containing reagents was added and the monolayers were 
pulsed with $2.5 \mu \mathrm{Ci}$ of $\left[5-6-{ }^{3} \mathrm{H}\right]$ uracil (specific activity $49 \mathrm{Ci} / \mathrm{mmol}$; Amersham plc, Buckinghamshire, England). After a 24-h period of incubation the radioactivity was counted in the acid-precipitable material by filtration procedure (Chang \& Pechère, 1988). The inhibition of the intracellular Tox. gondii growth rate was thus assessed by using $\left[{ }^{3} \mathrm{H}\right]$ uracil, a precursor which is incorporated by Tox. gondii, but not the host cells (Chang \& Pechère, 1988). In addition, the outcome of intracellular infection was assessed by microscopically counting the number of infected cells and the number of intracellular parasites per 100 cells in Giemsa-stained preparations. An antitoxoplasmic effect was indicated by a decrease in the parameters considered at $24 \mathrm{~h}$.

\section{Effects of electron carriers on extracellular toxoplasmas}

Fresh suspensions of Tox. gondii $\left(3-6 \times 10^{6}\right.$ tachyzoites $\left./ \mathrm{ml}\right)$ were incubated in $5 \%$ $\mathrm{CO}_{2}-95 \%$ air at $37^{\circ} \mathrm{C}$ with the electron carriers for $30 \mathrm{~min}$ at the desired concentrations. The suspensions were centrifuged at $50 \mathrm{~g}$ for $10 \mathrm{~min}$, washed with phosphate-buffered saline ( $\mathrm{pH} 7.2$ ), centrifuged again and resuspended in $\mathrm{M} 199$ with $3 \%$ FCS. They were used to challenge macrophage monolayers for $\left[{ }^{3} \mathrm{H}\right]$ uracil experiments and for Giemsa-stained preparations.

\section{Effect of electron carriers on antitoxoplasmic activity of resident macrophages}

Mouse macrophage monolayers were exposed for $24 \mathrm{~h}$ to the electron carriers at the desired concentrations. At the end of the incubation period, the monolayers were washed three times with prewarmed HBSS and challenged with freshly harvested Tox. gondii for $1 \mathrm{~h}$. Assessment of Tox. gondii inhibition was made after a 24-h incubation period in medium without the electron carriers.

\section{Assessment of toxicity on macrophages}

Adherent macrophage monolayer cells were incubated for $24 \mathrm{~h}$ with different concentrations of the electron carriers and their viability was assessed as described previously (Chang \& Pechère, 1988), by the trypan blue dye exclusion test. In addition, macrophage monolayers were examined in Giemsa-stained preparations, after $24 \mathrm{~h}$ incubation, for the number of cells per high power field and assessed for their morphological characteristics.

\section{Statistics}

Data are reported as the mean \pm standard error of the mean (SEM). The $50 \%$ inhibitory concentrations $\left(\mathrm{IC}_{30}\right)$, the $95 \%$ confidence limits, and the $\mathrm{IC}_{90}$ were calculated by probit analysis following the method of Litchfield \& Wilcoxon (1949). differences between values were analyzed by the Student's t-test. A P value $<0.05$ was considered significant.

\section{Results}

\section{Activity of electron carriers on intracellular toxoplasmas}

Infected murine peritoneal macrophages were exposed to increasing amounts of the electron carriers in concentrations from 0.001 to $35 \mu \mathrm{M}$, and the growth rate of 
Table I. Activity of cationic electron carriers against intracellular Tox. gondii as assessed by $\left[{ }^{3} \mathrm{H}\right] \mathrm{uracil}$ assay

\begin{tabular}{|c|c|c|}
\hline $\begin{array}{l}\text { Treatment of infected } \\
\text { macrophages }\end{array}$ & $\begin{array}{c}50 \% \text { Inhibitory } \\
\left.\text { concentration (IC }{ }_{50}\right) \\
(\mu \mathrm{M})(95 \% \text { fiducial } \\
\text { range) }\end{array}$ & $\begin{array}{c}90 \% \text { Inhibitory } \\
\text { concentration }\left(\mathrm{IC}_{90}\right) \\
(\mu \mathrm{M})\end{array}$ \\
\hline $\begin{array}{l}\text { Crystal violet } \\
\text { Phenazine }\end{array}$ & $0.26(0.18-0.37)$ & 0.43 \\
\hline $\begin{array}{l}\text { methosulphate } \\
\text { Methylene blue } \\
\text { Brilliant cresyl blue }\end{array}$ & $\begin{array}{l}1.35(1.00-2.25) \\
0.45(0.13-1.50) \\
1.52(0.91-2.53)\end{array}$ & $\begin{array}{l}2 \cdot 38 \\
2 \cdot 38 \\
3 \cdot 24\end{array}$ \\
\hline
\end{tabular}

intracellular Tox. gondii was assessed by measuring the uptake of $\left[{ }^{3} \mathrm{H}\right]$ uracil over a period of $24 \mathrm{~h}$. Micromolar concentrations of all electron carriers tested were able to restrict the intracellular multiplication of the parasite. This allowed calculation of their $\mathrm{IC}_{50}$ and $\mathrm{IC}_{90}$ as shown in Table I. Table II summarizes the results of experiments performed with microscopically assessed preparations. All electron carriers at their respective $\mathrm{IC}_{90}$, according to the $\left[{ }^{3} \mathrm{H}\right]$ uracil incorporation studies, significantly reduced the number of infected cells and the number of toxoplasmas per 100 cells, and at higher concentrations allowed complete eradication of the parasites from the macrophages. These effects were seen at concentrations which were not toxic for the macrophages according to the trypan blue dye exclusion test and morphological criteria. By raising the concentrations, toxic effects on the cells however, appeared with increased concentrations of crystal violet, phenazine methosulphate and methylene blue (Table II).

\section{Effect of electron carriers on extracellular toxoplasmas}

The electron carriers did not alter the viability of extracellular Tox. gondii, assessed by their ability to reinfect macrophage cultures (Table III).

Table II. Activity of cationic electron carriers against intracellular Tox. gondii as assessed by microscopy

\begin{tabular}{|c|c|c|c|c|}
\hline \multicolumn{2}{|c|}{$\begin{array}{l}\text { Treatment of infected } \\
\text { macrophages with } \\
\text { electron carriers }(\mu \mathrm{M})\end{array}$} & \multirow{3}{*}{$\begin{array}{c}\begin{array}{c}\% \text { of } \\
\text { infected } \\
\text { cells }\end{array} \\
56 \pm 4 \\
0^{4} \\
8 \pm 1 \\
0^{4}\end{array}$} & \multirow{3}{*}{$\begin{array}{c}\begin{array}{c}\text { Number of } \\
\text { toxoplasmas } \\
\text { per } 100 \text { cells }\end{array} \\
717 \pm 8 \\
\sigma^{\circ} \\
16 \pm 1^{c} \\
0^{\circ}\end{array}$} & \multirow[t]{2}{*}{$\begin{array}{l}\text { Minimal concentration } \\
\text { for toxicity to macrophage } \\
\text { monolayers }(\mu \mathrm{M})^{3}\end{array}$} \\
\hline $\begin{array}{l}\text { Medium only } \\
\text { Crystal violet }\end{array}$ & $\begin{array}{r}\text { (control) } \\
(0.43)\end{array}$ & & & \\
\hline $\begin{array}{l}\text { Phenazine } \\
\text { methosulphate }\end{array}$ & $\begin{array}{r}(2 \cdot 38) \\
(5)\end{array}$ & & & 7 \\
\hline Methylene blue & $\begin{array}{r}(2 \cdot 38) \\
(15)\end{array}$ & ${ }^{7} \pm 1^{6}$ & $0^{6}$ & 30 \\
\hline Brilliant cresyl blue & $\begin{array}{r}(3.24) \\
(31)\end{array}$ & $\frac{5 \pm 1^{\circ}}{0^{2}}$ & $\sigma^{11 \pm 1^{c}}$ & No toxicity up to 35 \\
\hline
\end{tabular}

Results are the mean \pm sex of three experiments.

-Assessed by trypan blue dye exclusion and morphological criteria.

' $P<0.01$, compared to control; ' $P<0-001$, compared to control; $C P<0-0001$, compared to control; $P<0-00001$, compared to control. 
Table III. Effect of cationic electron carriers on extracellular Tox. gondii as assessed by subculture

\begin{tabular}{lcccc}
\hline $\begin{array}{l}\text { Pretreatment with } \\
\text { electron carriers }(\mu \mathrm{M})\end{array}$ & & $\begin{array}{c}\% \text { of infected } \\
\text { cells }\end{array}$ & $\begin{array}{c}\text { Number of toxoplasmas } \\
\text { per } 100 \text { macrophages }\end{array}$ & $\begin{array}{c}\text { Incorporation of } \\
\text { ['H]uracile }\end{array}$ \\
\hline Extracellular Tox. gondii & & & & \\
None & & $49 \pm 1$ & $629 \pm 6$ & 100 \\
Crystal violet & $(0-43)$ & $48 \pm 2$ & $611 \pm 7$ & $94 \pm 8 \cdot 3$ \\
Phenazine methosulphate & $(2 \cdot 38)$ & $53 \pm 2$ & $665 \pm 9$ & $98 \pm 9 \cdot 1$ \\
Methylene blue & $(2 \cdot 38)$ & $51 \pm 1$ & $640 \pm 5$ & $99 \pm 6 \cdot 8$ \\
Brilliant cresyl blue & $(3.24)$ & $48 \pm 1$ & $614 \pm 8$ & $96 \pm 7 \cdot 5$ \\
\hline
\end{tabular}

Results are the mean \pm sew of three experiments.

Expressed as percentage of intracellular inhibition: $(100-\mathrm{cpm}$ in teat/cpm in control) $\times 100$.

\section{Effect on anti-toxoplasma activity of resident macrophages}

In order to test whether or not these compounds produced some degree of macrophage activation, we incubated resident macrophage monolayers with the different electron carriers for $24 \mathrm{~h}$, and challenged them with Tox. gondii. None of the tested electron carriers was able to enhance the antitoxoplasmic activity of the resident mouse macrophages (Table IV).

\section{Effect of scavengers of oxygen intermediates}

We further investigated the effect of scavengers of oxygen intermediates on the activity of the cationic electron carriers at their corresponding $\mathrm{IC}_{90}$. The scavengers of ROI did not block the ability of electron carriers to kill intracellular Tox. gondii at the concentrations tested (Table V).

\section{Discussion}

These studies showed that electron carriers were toxoplasmacidal in vitro at micromolar concentrations; the parasites were completely eradicated from the macrophages at some of the concentrations tested. The combination of pyrimethamine

Table IV. Effect of cationic electron carriers on antitoxoplasmic activity of macrophages

\begin{tabular}{|c|c|c|c|c|}
\hline $\begin{array}{l}\text { Pretreatment with } \\
\text { electron carriers ( } \mu \mathrm{M})\end{array}$ & & $\begin{array}{l}\% \text { of infected } \\
\text { cells }\end{array}$ & $\begin{array}{l}\text { Number of toxoplasmas } \\
\text { per } 100 \text { macrophages }\end{array}$ & $\begin{array}{c}\text { Incorporation of } \\
{\left[{ }^{3}{ }^{H}\right] \text { uracil }}\end{array}$ \\
\hline $\begin{array}{l}\text { Resident mouse macropha } \\
\text { None } \\
\text { Crystal violet } \\
\text { Phenazine methosulphate } \\
\text { Methylene blue } \\
\text { Brilliant cresyl blue }\end{array}$ & $\begin{array}{l}(0-43) \\
(2 \cdot 38) \\
(2 \cdot 38) \\
(3 \cdot 24)\end{array}$ & $\begin{array}{l}47 \pm 1 \\
45 \pm 2 \\
51 \pm 2 \\
47 \pm 3 \\
50 \pm 2\end{array}$ & $\begin{array}{l}597 \pm 8 \\
591 \pm 7 \\
628 \pm 9 \\
594 \pm 6 \\
583 \pm 12\end{array}$ & $\begin{array}{c}100 \\
95 \pm 3 \cdot 8 \\
93 \pm 7 \cdot 6 \\
94 \pm 7.8 \\
97 \pm 5 \cdot 3\end{array}$ \\
\hline
\end{tabular}

Results are the mean $t$ seas of three experiments.

Expressed as percentage of intracellular inhibition: (100-cpm in test/cpm in control) $\times 100$. 
Table V. Effects of scavengers of oxygen intermediates on the activity of cationic electron carriers against intracellular Tox. gondit

\begin{tabular}{lcrrrr}
\hline $\begin{array}{l}\text { Treatment of infected } \\
\text { macrophages }\end{array}$ & None & $\begin{array}{c}\text { Crystal } \\
\text { violet }\end{array}$ & $\begin{array}{c}\text { Phenazine } \\
\text { methosulphate }\end{array}$ & $\begin{array}{c}\text { Methylene } \\
\text { blue }\end{array}$ & $\begin{array}{c}\text { Brilliant } \\
\text { cresyl blue }\end{array}$ \\
\hline Medium only & 100 & $8.5 \pm 1.3$ & $16.8 \pm 2.3$ & $15.5 \pm 3.8$ & $16.9 \pm 3.5$ \\
Catalase (2.5 mg/ml) & $102 \pm 5.7$ & $4.9 \pm 0.7$ & $21.3 \pm 2.7$ & $23.5 \pm 1.0$ & $19.4 \pm 1.0$ \\
Superoxide dismutase $(2.5 \mathrm{mg} / \mathrm{ml})$ & $96 \pm 6.9$ & $4.9 \pm 0.8$ & $24.8 \pm 3.0$ & $17.3 \pm 3.2$ & $25.5 \pm 3.1$ \\
Histidine (10 mM) & $97 \pm 7.9$ & $10.0 \pm 1.3$ & $21.9 \pm 2.4$ & $16.8 \pm 2.4$ & $14.0 \pm 2.2$ \\
Diazabicyclooctane (mM) & $94 \pm 9.7$ & $6.8 \pm 1.9$ & $18.1 \pm 2.6$ & $19.7 \pm 3.5$ & $13.7 \pm 0.5$ \\
Mannitol (50 mM) & $99 \pm 5.2$ & $10.7 \pm 2.1$ & $13.0 \pm 3.5$ & $19.7 \pm 3.6$ & $17.5 \pm 0.8$ \\
Benzoic acid (25 mM) & $97 \pm 6.8$ & $5.7 \pm 0.9$ & $11.2 \pm 1.6$ & $18.3 \pm 2.1$ & $17.8 \pm 1.0$ \\
Tetramethylurea (25 mM) & $98 \pm 5.3$ & $5.2 \pm 1.2$ & $13.0 \pm 1.2$ & $19.4 \pm 1.8$ & $13.9 \pm 0.3$ \\
\hline
\end{tabular}

Measured by [3 H]uracil assay, and expressed as percentage of intracellular inhibition as stated in Table III and IV.

The electron carriers were added at their respective $90 \%$ inhibitory concentrations as shown in Table I.

and sulphadiazine, investigated in a similar system, was also active against Tox. gondii at the micromolar level, but exerted less killing effect (Chang \& Pechère, 1988).

The electron carriers could have stimulated the macrophages to kill the parasites or could have acted directly on the intracellular parasites. Regarding a macrophagemediated mechanism, some studies have suggested that the intracellular killing of leishmania by electron carriers, excepting crystal violet, correlated with the stimulation of the hexose monophosphate shunt, and with the generation of ROI (Mauel et al., 1984). Here, stimulation of the release of ROI was unlikely since the antitoxoplasma activity of the electron carriers was not altered by the scavengers of ROI. Pretreatment of macrophages with electron carriers did not enhance the antitoxoplasmic activity of these cells, an observation which also tips the balance in favour of a direct antiparasitic effect. Since the electron carriers were not active against extracellular Tox. gondii, but only against actively growing intracellular parasites, an interference with the parasites' metabolism by the electron carriers is suggested. Some arguments for direct damage to the intracellular parasites can be found elsewhere. Phenazine methosulphate has been found to accumulate in the parasitophorous vacuoles of macrophages infected with leishmania (Rabinovitch et al., 1982). A mechanism for a direct anti-Tryp. cruzi effect has been proposed for crystal violet, consisting in a photodynamic action apparently mediated by the formation of carbon-centred free radicals in the parasites themselves (Docampo et al., 1983). An alternative mechanism could be direct oxidative damage to the parasites. In this view, a correlation of between toxoplasmacidal action and the redox potential of the electron carriers would have been expected. This was not the case, here, nor with other intracellular parasites also susceptible to the electron carriers (Rabinovitch et al., 1982; Alves \& Rabinovitch, 1983; Mauel et al., 1984). However, such correlation is likely to be obscured by other structural requirements for drug permeation (Rabinovitch et al., 1983; Mauel et al., 1984).

In conclusion, we have shown that these electron carriers are toxoplasmacidal, but the mechanisms of their impressive activity remain unclear. Further investigation is warranted with these and related compounds because of their interesting chemotherapeutic perspective. 


\section{Acknowledgements}

This work was supported in part by grant $3.221-085$ from the Fonds National Suisse de la Recherche Scientifique and in part by grant G4/88 from the Finanz-Pool 3R Foundation.

\section{References}

Alves, M. J. M. \& Rabinovitch, M. (1983). Destruction of intracellular Trypanosoma cruzi after treatment of infected macrophages with cationic electron carriers. Infection and Immunity $39,435-8$.

Catterall, J. R., Sharma, S. D. \& Remington, J. S. (1986). Oxygen-independent killing by alveolar macrophages. Journal of Experimental Medicine 163, 1113-31.

Chang, H. R. \& Pechère, J.-C. F. (1988). In vitro effects of four macrolides (roxithromycin, spiramycin, axithromycin [CP-62,993], and A-56268) on Toxoplasma gondii. Antimicrobial Agents and Chemotherapy 32, 524-9.

Docampo, R., Moreno, S. N. J., Muniz, R. P. A., Cruz, F. S. \& Mason, R. P. (1983). Lightenhanced free radical formation and trypanocidal action of gentian violet (crystal violet). Science 220, 1292-5.

Hassan, H. M. \& Fridovich, I. (1979). Intracellular production of superoxide radical and of hydrogen peroxide by redox active compounds. Archives of Biochemistry and Biophysics 196, 385-95.

Litchfield, J. T. \& Wilcoxon, F. (1949). Simplified method of evaluating dose-effect experiments. Joumal of Pharmacology and Experimental Therapeutics 96, 99-113.

Mauel, J., Schnyder, J. \& Baggiolini, M. (1984). Intracellular parasite killing induced by electron carriers. II. Correlation between parasite killing and the induction of oxidative events in macrophages. Molecular and Biochemical Parasitology 13, 97-110.

Murray, H. W., Spitalny, G. L. \& Nathan, C. F. (1985). Activation of mouse peritoneal macrophages in vitro and in vivo by interferon- $\gamma$. Journal of Immunology 134, 1619-22.

Nathan, C. F., Murray, H. W., Wiebe, M. E. \& Rubin, B. Y. (1983). Identification of interferon- $y$ as the lymphokine which activates human macrophage oxidative metabolism and antimicrobial activity. Journal of Experimental Medicine 158, 670-89.

Nussenzweig, V., Sonntag, R., Biancalana, A., Pedreira de Freitas, J. L., Amado Neto, V. \& Kloetzel, J. (1953) Açãode corantes trifenil-metánicos sôbre o Trypanosoma cruzi 'in vitro'. Emprêgo de violeta de genciana na profilaxia da transmissão da moléstia de Chagas por transfusão de sangue. Hospital (Rio de Janeiro) 44, 731-44.

Rabinovitch, M., Dedet, J.-P., Ryter, A., Robineaux, R., Topper, G. \& Brunet, E. (1982). Destruction of Leishmania mexicana amazonensis amastigotes within macrophages in culture by phenazine methosulfate and other electron carriers. Journal of Experimental Medicine 155, 415-31.

(Received 14 September 1988; accepted 12 October 1988) 